\title{
Analisis Pemilihan Tempat Pembuangan Limbah Medis Menggunakan Metode Topsis
}

\author{
Muhammad Ardiansyah Sembiring1, Donni Nasution², Mustika Fitri larasati Sibuea ${ }^{3}$ \\ Sekolah Tinggi Manajemen Infromatika dan Komputer Royal \\ Jl. Prof.H.M.Yamin No.173, Kisaran, Sumatera Utara, Indonesia 21222 \\ Email : adinmantap88@gmail.com
}

\begin{abstract}
Various types of medical waste produced from service activities in hospitals can endanger and cause health problems, especially during collection, sorting, shelter, storage, transportation and destruction and final disposal. In terms of disposal of medical waste, most existing hospitals work with other companies in the processing and disposal of their medical waste because there is no official medical waste disposal site available. With the above problems, the researchers are interested in conducting a research process to assist the relevant agencies in finding a solution to determine the location of appropriate disposal of medical waste through the application of information technology. The method used in this study is the TOPSIS (Technique for Others Reference by Similarity to Ideal Solution) method, which is one method in the Decision Support System (SPK). Based on the results and previous discussion, it can be concluded that Mandoge is the main choice in choosing the right place as a place for disposal of medical waste because it has the necessary criteria. Therefore the application of the topsis method can help determine good alternatives in a decision-making system for selecting the best Medical Waste disposal sites.
\end{abstract}

Keywords: DSS, TOPSIS, Medical Waste.

\begin{abstract}
Abstrak-Berbagai jenis limbah medis yang dihasilkan dari kegiatan pelayanan di rumah sakit dapat membahayakan dan menimbulkan gangguan kesehatan terutama pada saat pengumpulan, pemilahan, penampungan, penyimpanan, pengangkutan dan pemusnahan serta pembuangan akhir. Dalam hal pembuangan limbah medis kebanyakan rumah sakit yang ada bekerja sama dengan perusahaan lain dalam hal pengolahan juga pembuangan limbah medis mereka di karenakan tidak ada nya tempat pembuangan limbah medis yang berijin resmi tersedia. Dengan adanya permasalahan di atas maka peneliti tertarik untuk melakukan proses penelitian guna membantu dinas terkait dalam mendapatkan solusi untuk menentukan lokasi pembuangan limbah medis yang tepat melalui penerapan teknologi informasi. Metode yang digunakan pada penelitian ini adalah metode TOPSIS (Technique For Others Reference by Similarity to Ideal Solution) yang merupakan salah satu metode pada Sistem Pendukung Keputusan (SPK). Berdasarkan hasil dan pembahasan sebelumnya maka dapat disimpulkan sebagai bahwa Mandoge menjadi pilihan utama dalam memilih tempat yang tepat sabagai tempat pembuangan limbah medis karna memiliki kriteria yang diperlukan. Maka dari itu penerapan metode topsis dapat membantu menentukan alternatif yang baik dalam sebuah sistem pengambil keputusan untuk pemilihan tempat pembuangan Limbah Medis terbaik.
\end{abstract}

Kata Kunci : SPK, TOPSIS, Limbah Medis

\section{PENDAHULUAN}

Karakteristik utama limbah pelayanan kesehatan adalah adanya limbah medis dan limbah non medis. Berbagai jenis limbah medis yang dihasilkan dari kegiatan pelayanan di rumah sakit dapat membahayakan dan menimbulkan gangguan kesehatan terutama pada saat pengumpulan, pemilahan, penampungan, penyimpanan, pengangkutan dan pemusnahan serta pembuangan akhir. ICRC mengemukakan tentang resiko kesehatan akibat limbah medis, dibagi dalam lima kategori yakni resiko terjadinya trauma, resiko terjadinya infeksi, resiko zat kimia, 
resiko ledakan/ terbakar, dan resiko radioaktif [1]. Dalam hal ini pemilihan teknologi yang tepat dapat membantu dinas terkait dalam penanganan limbah medis agar tidak terjadi pencemaran. Sala satu yang terpenting adalah teknologi dalam pemilihan lokasi pembuangan limbah medis yang tepat. Dalam hal pembuangan limbah medis kebanyakan rumah sakit yang ada bekerja sama dengan perusahaan lain dalam hal pengolahan juga pembuangan limbah medis mereka di karenakan tidak ada nya tempat pembuangan limbah medis yang berijin resmi tersedia. Hal ini menyebabkan pengeluaran biaya operasional rumah sakit bertambah besar hanya untuk membuang limbah medis mereka. Sama halnya pada lokasi pengamatan yang peneliti lakukan di kota kisaran Kab. Asahan, belum tersedianya teknologi yang tepat dalam penanganan pembuangan limbah medis yang tersedia. Kurangnya perhatian pemerintah dalam penanganan limbah medis di daerah menyebabkan rumah sakit di daerah ini harus mengeluarkan biaya lebih dalam proses pembuangan limbah medis mereka.

Dengan adanya permasalahan di atas maka peneliti tertarik untuk melakukan proses penelitian guna membantu dinas terkait dalam mendapatkan solusi untuk menentukan lokasi pembuangan limbah medis yang tepat melalui penerapan teknologi informasi. Metode yang digunakan pada penelitian ini adalah metode TOPSIS (Technique For Others Reference by Similarity to Ideal Solution) yang merupakan salah satu metode pada Sistem Pendukung Keputusan (SPK). Melalui penerapan metode ini, peneliti akan membandingkan beberapa lokasi yang dipilih berdasarkan kriteria yang menentukan suatu lokasi dikatakan baik. Seperti kriteria harga, luas lokasi, jarak, resiko, dan kriteria lainnya Sehingga akan menghasilkan sebuah informasi tentang lokasi yang tepat berdasarkan semua kriteria yang ada. Melalui pembuatan sistem pendukung keputusan dalam pemilihan lokasi yang tepat dalam pembuangan limbah medis, diharapkan dapat membantu dinas terkait dalam menentukan lokasi pembuangan limbah yang tepat di daerah nya masing-masing. Metode TOPSIS adalah salah satu metode pengambilan keputusan multikriteria yang pertama kali diperkenalkan oleh Yoon dan Hwang (1981). TOPSIS menggunakan prinsip bahwa alternatif yang terpilih harus mempunyai jarak terdekat dari solusi ideal positif dan terjauh dari solusi ideal negatif dari sudut pandang geometris dengan menggunakan jarak Euclidean untuk menentukan kedekatan relatif dari suatu alternatif dengan solusi optimal [2], [3].

\subsection{Limbah Medis}

Limbah medis adalah limbah yang berasal dari kegiatan pelayanan medis. Berbagai jenis limbah medis yang dihasilkan dari kegiatan pelayanan di rumah sakit dapat membahayakan dan menimbulkan gangguan kesehatan terutama pada saat pengumpulan, pemilahan, penampungan, penyimpanan, pengangkutan dan pemusnahan serta pembuangan akhir [4]

\subsection{Metode TOPSIS}

TOPSIS diperkenalkan pertama kali oleh Yoon dan Hwang pada tahun 1981 untuk digunakan sebagai salah satu metode dalam memecahkan masalah multikriteria. TOPSIS memberikan sebuah solusi dari sejumlah alternatif yang Pemilihan Tempat Pembuangan Limbah Medis (Muahammad Ardiansyah Sembiring) | 1115 
mungkin dengan cara membandingkan setiap alternatif dengan alternatif terbaik dan alternatif terburuk yang ada diantara alternatif-alternatif masalah[5].

\subsection{Sistem Pendukung Keputusan}

Sistem pendukung keputusan (SPK) adalah sistem berbasis komputer yang interaktif, yang membantu pengambil keputusan memanfaatkan data dan model untuk menyelesaikan masalah-masalah yang tak terstruktur dan semi terstruktur[6].

\section{METODOLOGI PENELITIAN}

\subsection{Prosedur Penelitian}

Adapun kerangka kerja dari penelitian ini yaitu, Studi Pendahuluan, Menentukan Tujuan, Mengumpulkan Data, Analisa Masalah, Pengolahan Data dengan Metode TOPSIS.

\subsection{Analisis Data}

Secara umum, prosedur TOPSIS mengikuti langkah-langkah sebagai berikut:

a. Membuat matriks keputusan yang ternormalisasi

b. Membuat matriks keputusan yang ternormalisasi terbobot

c. Menentukan matriks solusi ideal positif dan matriks solusi ideal negatif

d. Menentukan jarak antara nilai setiap alternatif dengan matriks solusi ideal positif dan matriks solusi ideal negatif

e. Menentukan nilai preferensi untuk setiap alternatif.

TOPSIS membutuhkan rating kerja setiap alternatif Ai pada setiap kriteria $\mathrm{Cj}$ yang ternormalisasi.

$$
\mathrm{r}_{\mathrm{ij}}=\frac{x_{i j}}{\sqrt{\sum_{i=1}^{m} x_{i j}^{2}}}
$$

dengan $i=1,2, \ldots, m ;$ dan $j=1,2, \ldots, n$,

Keterangan:

$\mathrm{r}_{\mathrm{ij}}=$ matriks ternormalisasi [i][j]

$\mathrm{x}_{\mathrm{ij}}=$ matriks keputusan $[\mathrm{i}][\mathrm{j}]$

Solusi ideal positif A+ dan solusi ideal negatif A- dapat ditentukan berdasarkan rating bobot ternormalisasi (yij) sebagai:

$\mathrm{Y}_{\mathrm{ij}}=$ wi.rij; dengan $\mathrm{i}=1,2, \ldots, \mathrm{m} ;$ dan $\mathrm{j}=1,2, \ldots, \mathrm{n}$

$A+=(y 1+, y 2+, \ldots, y n+)$

A- $\quad=(y 1-, y 2-, \ldots, y n-)$;

$\mathrm{Di}+=\sqrt{\sum_{i=1}^{n}\left(y_{i}^{+}-y_{i j}\right)^{2}}$ 


$$
\mathrm{D}_{\mathrm{i}}^{-}=\sqrt{\sum_{j=1}^{n}\left(y_{i j}-y_{i}^{-}\right)^{2}}
$$

Keterangan:

$\mathrm{y}_{\mathrm{ij}}=$ matriks ternormalisasi terbobot $[\mathrm{i}][\mathrm{j}]$

$\mathrm{w}_{\mathrm{i}}=$ vektor bobot[i] dari proses AHP

$\mathrm{y}_{\mathrm{j}}+=\max \mathrm{yij}$, jika $\mathrm{j}$ adalah atribut keuntungan min yij, jika $\mathrm{j}$ adalah atribut biaya

$\mathrm{y}_{\mathrm{j}^{-}}=$min yij, jika $\mathrm{j}$ adalah atribut keuntungan max yij, jika $\mathrm{j}$ adalah atribut biaya

$\mathrm{j} \quad=1,2, \ldots, \mathrm{n}$ Jarak antara alternatif Ai dengan solusi ideal positif:

i $\quad=1,2, \ldots, \mathrm{m}$

Nilai preferensi untuk setiap alternatif (Vi) dapat dilihat pada

$$
\begin{aligned}
& \mathrm{Vi}=; \mathrm{i}=1,2, \ldots, \mathrm{m} \\
& \mathrm{Vi}=\frac{D_{i}^{-}}{D_{i}^{-}+D_{i}^{+}} ; \mathrm{i}=1,2, \ldots, \mathrm{m}
\end{aligned}
$$

Keterangan:

$\mathrm{Vi}$ = kedekatan tiap alternatif terhadap solusi ideal

$\mathrm{D}_{\mathrm{i}}+=$ jarak alternatif Ai dengan solusi ideal positif

$\mathrm{D}_{\mathrm{i}^{-}}=$jarak alternatif Ai dengan solusi ideal negatif

Nilai Vi yang lebih besar menunjukkan bahwa alternatif Ai lebih dipilih.

\section{HASIL DAN PEMBAHASAN}

Dalam proses pemilihan tempat pembuangan limbah medis terbaik yang dilakukan dengan menggunakan TOPSIS diperlukan kriteria-kriteria, bobot kepentingan setiap kriteria dan rating kecocokan alternatif terhadap kriteria untuk melakukan perhitungan sehingga akan didapatkan alternatif terbaik.Maka dari itu peneliti menulis bahwa $A_{1}$ itu sama dengan alternatif 1 , peneliti juga mengelompokan antara $A_{1}$ dengan sumber data yang ada dapat dilihat pada tabel 1 berikut:

Tabel 1. Alternatif

\begin{tabular}{|l|l|}
\hline Alternatif & Keterangan \\
\hline$A_{1}$ & Mandoge \\
\hline$A_{2}$ & Tinggi Raja \\
\hline$A_{3}$ & Sungai Silau \\
\hline$A_{4}$ & Tanah Jawa \\
\hline$A_{5}$ & Sambahuta \\
\hline
\end{tabular}

Sedangkan kriteria-kriteria yang digunakan terlihat dalam tabel berikut ini:

Tabel 2. Kriteria

\begin{tabular}{|l|l|}
\hline Kriteria & Keterangan \\
\hline $\mathrm{C}_{1}$ & Luas Lahan \\
\hline $\mathrm{C}_{2}$ & Resiko Pencemaran \\
\hline $\mathrm{C}_{3}$ & Jarak \\
\hline
\end{tabular}




\begin{tabular}{|l|l|}
\hline $\mathrm{C}_{4}$ & Harga Tanah \\
\hline
\end{tabular}

Keterangan tabel 2 untuk keriteria yaitu $C_{1}$ (Luas Tanah), $C_{2}$ (Resiko Pencemaran), $C_{3}$ (Jarak), $C_{4}$ (Harga Tanah). Di mana bobot kepentingan kriteria ini berdasarkan dari observasi, terdapat dua kriteria yaitu $C_{2}$, dan $C_{4}$ yang memiliki bobot kepentingan 5 , satu kriteria yaitu, $C_{1}$, yang memiliki bobot kepentingan 4 ,dan satu criteria yaitu, $C_{3}$ memiliki bobot kepentingan 3 .

Tabel 3 Bobot Rating Kepentingan Untuk Setiap Criteria

\begin{tabular}{|l|l|l|l|l|}
\hline Kriteria & $\mathrm{C}_{1}$ & $\mathrm{C}_{2}$ & $\mathrm{C}_{3}$ & $\mathrm{C}_{4}$ \\
\hline Rating & 4 & 5 & 3 & 5 \\
\hline
\end{tabular}

Tabel 4. Matriks perbandingan alternatif dan kriteria

\begin{tabular}{|l|l|l|l|l|}
\hline \multirow{2}{*}{ Alternatif } & \multicolumn{4}{|l|}{ Rating kecocokan } \\
\cline { 2 - 5 } & $\mathrm{C}_{1}$ & $\mathrm{C}_{2}$ & $\mathrm{C}_{3}$ & $\mathrm{C}_{4}$ \\
\hline $\mathrm{A}_{1}$ & 4 & 5 & 3 & 4 \\
\hline $\mathrm{A}_{2}$ & 3 & 2 & 5 & 5 \\
\hline $\mathrm{A}_{3}$ & 5 & 3 & 4 & 3 \\
\hline $\mathrm{A}_{4}$ & 5 & 4 & 2 & 4 \\
\hline $\mathrm{A}_{5}$ & 2 & 3 & 3 & 2 \\
\hline
\end{tabular}

Pada kolom $C_{1}$ baris $A_{1}$ terdapat Matriks perbandingan 4, 5, 3 dan 4 Matris perbandingan ini didapatkan berdasarkan dari observasi dan kuisioner, menggambarkan nilai perbandingan antara kolom $C_{1}$ baris $A_{1}$, kolom $C_{1}$ baris $A_{2}$ terdapat matriks perbandingan $3,2,5$ dan 5 , kolom $\mathrm{C}_{1}$ baris $\mathrm{A}_{3}$ terdapat matriks perbandingan $5,3,4$, dan 3 , kolom $\mathrm{C}_{1}$ baris $\mathrm{A}_{4}$ terdapat matriks perbandingan $5,4,2$ dan 4 Selanjutnya kolom $C_{1}$ baris $A_{5}$ terdapat matriks perbandingan 2,3,3 dan 2 . Langkah selanjutnya yaitu menghitung matriks keputusan ternomalisasi

Tabel 5. Matriks Keputusan Ternomalisasi

\begin{tabular}{|l|l|l|l|l|}
\hline A/K & Luas Tanah & Resiko Pencemaran & Jarak & Harga Tanah \\
\hline$A_{1}$ & 0,45003516 & 0,56254395 & 0,377964473 & 0,478091444 \\
\hline$A_{2}$ & 0,33752637 & 0,22501758 & 0,629940788 & 0,597614305 \\
\hline$A_{3}$ & 0,56254395 & 0,33752637 & 0,503952631 & 0,358568583 \\
\hline$A_{4}$ & 0,56254395 & 0,45003516 & 0,251976315 & 0,478091444 \\
\hline$A_{5}$ & 0,22501758 & 0,33752637 & 0,377964473 & 0,239045722 \\
\hline
\end{tabular}

Langkah selanjutnya yaitu menghitung matriks ternomalisasi terbobot dengan cara nilai matriks perbandingan ternomalisasi di kalikan dengan bobot.

Tabel 6. Matriks perbandingan ternomalisasi di kalikan dengan bobot

\begin{tabular}{|l|l|l|l|l|}
\hline $\mathbf{A} / \mathbf{K}$ & Luas Tanah & Resiko Pencemaran & Jarak & Harga Tanah \\
\hline $\mathrm{A}_{1}$ & 1,800140641 & 2,812719752 & 1,133893419 & 2,390457219 \\
\hline $\mathrm{A}_{2}$ & 1,350105481 & 1,125087901 & 1,889822365 & 2,988071523 \\
\hline $\mathrm{A}_{3}$ & 2,250175802 & 1,687631851 & 1,511857892 & 1,792842914 \\
\hline
\end{tabular}

Pemilihan Tempat Pembuangan Limbah Medis (Muahammad Ardiansyah Sembiring) | 1118 


\begin{tabular}{|l|l|l|l|l|}
$\mathrm{A}_{4}$ & 2,250175802 & 2,250175802 & 0,755928946 & 2,390457219 \\
\hline $\mathrm{A}_{5}$ & 0,900070321 & 1,687631851 & 1,133893419 & 1,195228609 \\
\hline
\end{tabular}

Langkah selanjutnya mencari nilai Maxsimal dan Minimal. Nilai Maksimal dan Minimal untuk tiap keriteria diambil dari tabel matriks perbandingan ternomalisasi dan terbobot dan diambil dari nilai alternatif tertinggi yang berada di tabel 7.

Tabel 7. Nilai Max Tiap Kriteria berdasarkan alternatif

\begin{tabular}{|l|l|l|l|l|}
\hline & Luas Tanah & Resiko Pencemaran & Jarak & Harga Tanah \\
\hline MAX & 2,250175802 & 2,812719752 & 1,889822365 & 2,988071523 \\
\hline MIN & 0,900070321 & 1,125087901 & 0,755928946 & 1,195228609 \\
\hline
\end{tabular}
(D-)

Langkah selanjutnya yaitu mencari jarak solusi idel positif (D+) dan negatif

Tabel 8. Nilai D+ dan D-

\begin{tabular}{|c|c|c|c|c|c|}
\hline \multirow[t]{5}{*}{$\mathrm{D}+$} & Mandoge & 1,063533297 & \multirow[t]{5}{*}{ D- } & Mandoge & 2,28684 \\
\hline & Tinggi Raja & 1,912649432 & & Tinggi Raja & 2,16853 \\
\hline & Sungai Silau & 1,684414247 & & Sungai Silau & 1,75152 \\
\hline & Tanah Jawa & 1,399754564 & & Tanah Jawa & 2,12537 \\
\hline & Sambahuta & 2,621892805 & & Sambahuta & 0,67773 \\
\hline
\end{tabular}

$$
\begin{array}{ll}
\text { Mandoge } & =0,682563145 \\
& =2,66104 /(2,66104+1,356089426)=0,662423194 \\
\text { Tinggi raja } & =0,787832191 \\
& =2,84182 /(2,84182+0,765319728)=0,787832191 \\
\text { Sungai Silau } & =0,268632068 \\
& =0,98094 /(0,98094+2,670662959)=0,268632068 \\
\text { Tanah Jawa } & =0,504651781 \\
& =1,92891 /(1,92891+1,893352503)=0,504651781 \\
\text { Sambahuta } & =0,389867709 \\
& =1,63106 /(1,63106+2,552567206)=0,389867709
\end{array}
$$

Setelah semua langkah selesai dibuat maka langkah terakhir adalah menentukan peringkat dimana peringkat diambil dari Nilai yang paling tinggi. Hasil peringkat sebagai berikut: 1 . Mandoge $=0,682563145,2$. Tinggi Raja $=0,7878321913$. Tanah Jawa $=0,504651781$, , . Sambahuta $=0,389867709$ dan ke 5. Sungai Silau =0,268632068 Sambahuta $=0,389867709$.

\section{KESIMPULAN}

Berdasarkan hasil dan pembahasan sebelumnya maka dapat disimpulkan sebagai bahwa Mandoge menjadi pilihan utama dalam memilih tempat yang tepat sabagai tempat pembuangan limbah medis karna memiliki kriteria yang diperlukan. Maka dari itu penerapan Metode Topsis dapat membantu menentukan Pemilihan Tempat Pembuangan Limbah Medis (Muahammad Ardiansyah Sembiring) | 1119 
alternatif yang baik dalam sebuah sistem pengambil keputusan untuk pemilihan Tempat pembuangan Limbah Medis terbaik.

\section{DAFTAR PUSTAKA}

[1] Erryliani, 2010. Laporan Observasi Tentang Limbah Puskesmas di Puskesmas Blok A. KabupatenTanah Lembu.

[2] Kurniasih, D. L. (2017). Sistem pendukung keputusan pemilihan laptop dengan metode TOPSIS. Pelita Informatika: Informasi dan Informatika, 3(2).

[3] Zai, Y., Mesran, M., Nadeak, B., \& Saputra, I. (2017). Penerapan Technique For Orders Preference By Similarity To Ideal Solution (Topsis) Untuk Keputusan Pemberian Kredit Pada Calon Nasabah (studi kasus: pt. Ss finance). Jurnal Media Informatika Budidarma, 1(1).

[4] Rahno, D., Roebijoso, J., \& Leksono, A. S. (2015). Pengelolaan Limbah Medis Padat Di Puskesmas Borong Kabupaten Manggarai Timur Propinsi Nusa Tenggara Timur. Indonesian Journal of Environment and Sustainable Development, 6(1).

[5] Hidayat, L. N. (2014). Metode TOPSIS Untuk Membantu Pemilihan Jurusan Pada Sekolah Menengah Atas. Tugas Akhir Program Studi Informatika/Ilmu Komputer, Universitas Dian Nuswantoro. Semarang.

[6] Lemantara, J., Setiawan, N. A., \& Aji, M. N. (2013). Rancang Bangun Sistem Pendukung Keputusan Pemilihan Mahasiswa Berprestasi Menggunakan Metode AHP dan Promethee. Jurnal Nasional Teknik Elektro dan Teknologi Informasi, 2(1), 13-21 